\title{
A STUDY OF PAIN AND DEPRESSION IN PATIENTS WITH RHEUMATOID ARTHRITIS
}

\author{
Ramash Kuttiyil1, Shynu Raju²
}

${ }^{1}$ Assistant Professor, Department of Psychiatry, Government Medical College, Calicut.

2Junior Consultant, Department of Psychiatry, Government Mental Health Centre, Calicut.

\section{ABSTRACT}

\section{BACKGROUND}

Rheumatoid arthritis is a psychosomatic illness, in which psychological factors play a major role in disease process. Comorbid depression and physical pain are major contributing factors (Chandarna et al, ${ }^{1}$ Covic et al), ${ }^{2}$ but they are unevaluated and under detected (Brend Lowe et al). ${ }^{3}$

Aims and Objectives- To study the prevalence of depression and its association with pain symptoms in rheumatoid arthritis patients.

\section{MATERIALS AND METHODS}

Inclusion Criteria- Patients above 18 years with rheumatoid arthritis and without having acute severe physical problems, mental retardation, delirium or dementia.

Study Tools- ICD-10 DCR, Brief pain inventory, MADRS.

\section{RESULTS}

Out of the 100 patients, $86 \%$ are females and $66 \%$ belong to 30 - 50 age group and most of them are using steroids (74\%) and are having less than 10 years duration of illness (93\%). Severe pain intensity score (BPI 10 - 20) is present in 30\%, pain interference score is more than 20 in $46 \%$ of patients and the percentage of pain reduction with medication is only less than $30 \%$ in $38 \%$ of study population. Depression is present in $22 \%$ and the mean MADRS score is 32 . BPI pain intensity score (p value .0008), pain interference score ( $\mathrm{p}$ value .000) and pain reduction score ( $\mathrm{p}$ value .0003) are significantly related to depression. Intensity of depression assessed by MADRS is significantly correlated with above variables.

\section{CONCLUSION}

Depression is a common comorbidity in rheumatoid arthritis patients and the level of pain, interference of pain in daily life and reduction of pain with medication is significantly related to depression. The severity of depression is significantly correlated with the above variables.

\section{KEYWORDS}

Pain, Depression, Rheumatoid Arthritis.

HOW TO CITE THIS ARTICLE: Kuttiyil R, Raju S. A study of pain and depression in patients with rheumatoid arthritis. J. Evolution Med. Dent. Sci. 2018;7(08):1012-1015, DOI: 10.14260/jemds/2018/231

\section{BACKGROUND}

Rheumatoid arthritis is a chronic illness with joint damage, pain and disability. Aetiology and progression of it mainly depends on immune, neuroendocrine and psychological factors. Psychological factors have been associated with pain perception, personal assessment of disability, quality of life, illness behaviour and psychological disturbances such as depression (Levenson 2004).4 21\% patients have depression severe enough to warrant treatment (Murphy et al) 5 and this association is related to increased levels of pain (Dickens et al) and remain significant even after the degree of disease activity has been controlled (Callahan et al). ${ }^{6}$ Depression is mostly unrecognised and undertreated. This is due to increased focus on the physical aspect of the disease, coupled with misconception that depression is understandable, occurring secondary to pain and disability and treatment of depression is not appropriate or necessary (Rifkin A). ${ }^{7}$

'Financial or Other Competing Interest': None.

Submission 02-01-2018, Peer Review 02-02-2018,

Acceptance 08-02-2018, Published 19-02-2018.

Corresponding Author:

Dr. Shynu Raju,

Astu, Nellikode (P. O.),

Calicut-673016, Kerala, India.

E-mail: shynu.raju@gmail.com

DOI: $10.14260 /$ jemds $/ 2018 / 231$

\section{(c) (i) $(-)$}

Despite the enormity of psychological problems related to rheumatoid arthritis, there has been a lack of vigorous psychiatric researches in this area in our population.

\section{Aims and Objectives}

To study the prevalence of depression and the relation of pain variables with depression in patients with rheumatoid arthritis.

\section{MATERIALS AND METHODS Study Design}

The study was conducted in Calicut Govt. Medical College on outpatient basis from patients attending the Rheumatology Clinic. Those who had given the consent and satisfying American Rheumatism Association's criteria and above 18 years of age were taken for study. Patients with acute severe physical problems, dementia, delirium and mental retardation were excluded. Each patient was assessed by using Mini Plus, ICD 10 DCR, Brief Pain Inventory and the severity of depression was assessed by MADRS. Patients with and without depression were compared based on sociodemographic data and pain variables. Correlation between the severity of depression and the pain variables were also assessed. Chi-square and linear regression were used for 
statistical analysis. The data was analysed by using SPSS 12 for windows (SPSS Inc. 2003).

\section{Brief Pain Inventory}

Devised by Charles S Cleeland, PHD (1991), it is used to assess the intensity of pain as well as the interference in patient's life due to pain. The short form of the tool is used, and it has 9 questions and the ninth question has 7 subquestions from $\mathrm{A}$ to $\mathrm{G}$. The first question is a 'yes' or 'no' question and the second question is a diagrammatic representation of sites of pains. The items from 3 to 7 and 7 subsets of question in 9 are rated from 0 to 10 . Question 8 is about the percentage of pain relief with medication. The severity is rated as mild, moderate or severe based on numerical ratings. Mild- 1 to 4 ; Moderate- 5 to 6; Severe- 7 to 10.

\section{Miniplus}

MINI Neuropsychiatric Interview was designed as a brief structured interview for the major Axis I psychiatric disorders in DSM IV and ICD-10.

\section{ICD}

- 10 Classification of Mental and Behavioural Disorder.

- Diagnostic Criteria for Research (DCR).

\section{Montgomery-Asberg Depression Rating Scale (MADRS)}

Developed by Montgomery and Asberg (1979). It has 10 items, each rated on a 4-point scale. Snaith et al suggested MADRS as a good tool to measure the severity of depression and suggested cut-off points; 0 - 6: No depression; 7 - 19: Mild depression; 20 - 34: Moderate depression; 35 - 60: Severe depression.

\section{RESULTS}

Most of the patients were Middle Aged (30 - 50)- (66\%), Married (84\%), Hindu (66\%), Females (85\%) and from Rural Background (85\%). Primary or high school education were present in $92 \%$, but $60 \%$ were unemployed and $58 \%$ from low income group. Less than 10 years duration of illness is there in $93 \%$ and steroid use was present in $74 \%$ patients. RA factor is positive in $66 \%$ patients. Past and family history of depression are present only in $4 \%$ of patients.

BPI pain intensity score was between 20 and 30 in 30\% patients and 0 to 10 in $70 \%$ patients. More than $60 \%$ pain reduction with medication was noted in $46 \%$ patients and less than $30 \%$ pain reduction was noted in $38 \%$ patients. Clinical depression was present in $22 \%$ patients and the mean MADRS score was 32. Among the depressive patients most of them were middle aged (81\%), married (77\%), Hindu (68\%), females (90\%) from rural background $(77 \%)$ with high primary or high school education rate (95\%). $77 \%$ were unemployed and 68\% from low income group. 91\% were steroid users, $61 \%$ were RA factor positive, but past or family history of depression were present only in $9 \%$ of currently depressed patients.

\begin{tabular}{|c|c|c|c|}
\hline & Present & Absent & Total \\
\hline BPI Inten $0-10$ & 9 & 61 & 70 \\
\hline BPI Inten $10-20$ & 13 & 17 & 30 \\
\hline Total & 22 & 78 & 100 \\
\hline \multicolumn{3}{|c|}{ Table 1. Depression and BPI Intensity }
\end{tabular}

\begin{tabular}{|c|c|c|c|}
\hline \multicolumn{3}{|c|}{ Chi-square = } & 11.2527 \\
\hline \multicolumn{3}{|c|}{ Degrees of freedom $=$} & 1 \\
\hline \multicolumn{3}{|c|}{$\mathrm{P}$ value $=$} & 0.0008 \\
\hline & Present & Absent & Total \\
\hline Inter 0-20 & 3 & 50 & 53 \\
\hline Inter $20-40$ & 12 & 24 & 36 \\
\hline Inter $>40$ & 7 & 4 & 11 \\
\hline Total & 22 & 78 & 100 \\
\hline Table & sio & Pain & ence \\
\hline
\end{tabular}

Chi-square $=20.6461$, Degrees of freedom $=1, P$ value $=0.0000$

\begin{tabular}{|c|c|c|c|}
\hline & Present & Absent & Total \\
\hline \% of pain reduction $0-25$ & 15 & 23 & 38 \\
\hline \% of pain reduction $25-50$ & 4 & 12 & 16 \\
\hline \% of pain reduction $>50$ & 3 & 43 & 46 \\
\hline Total & 22 & 78 & 100 \\
\hline
\end{tabular}

Table 3. Depression and \% of Reduction of Pain

\begin{tabular}{|c|c|}
\hline Chi-square $=$ & 13.1290 \\
\hline Degrees of freedom $=$ & 1 \\
\hline P value $=$ & 0.0003 \\
\hline
\end{tabular}

\begin{tabular}{|c|c|c|c|c|}
\hline Variable & Coefficient & Std. Error & F-Test & P-Value \\
\hline Age & -0.075 & 0.096 & 0.6139 & 0.443527 \\
\hline Sex & -0.424 & 0.369 & 1.3219 & 0.265291 \\
\hline Domicile & -0.289 & 0.225 & 1.6527 & 0.214887 \\
\hline Education & -0.312 & 0.165 & 3.5536 & 0.075667 \\
\hline Employment & -0.295 & 0.225 & 1.7189 & 0.206317 \\
\hline Income & -0.075 & 0.198 & 0.1430 & 0.709756 \\
\hline M Status & 0.352 & 0.220 & 2.5604 & 0.126973 \\
\hline Duration & -0.248 & 0.172 & 2.0703 & 0.167356 \\
\hline MADRS & -0.959 & 0.343 & 7.8427 & 0.012293 \\
\hline Constant & 2.714 & 0.994 & 7.4577 & 0.013720 \\
\hline &
\end{tabular}

Table 4. Pain Intensity Correlation

Correlation Coefficient: $\mathrm{R} 2=0.43$

\begin{tabular}{|c|c|c|c|c|}
\hline Variable & Coefficient & Std. Error & F-Test & P-Value \\
\hline Age & 0.125 & 0.086 & 2.1032 & 0.165196 \\
\hline Sex & 0.188 & 0.185 & 1.0337 & 0.322754 \\
\hline Domicile & 0.397 & 0.226 & 3.0996 & 0.096289 \\
\hline Education & -0.154 & 0.194 & 0.6323 & 0.436876 \\
\hline Employment & 0.149 & 0.203 & 0.5392 & 0.472782 \\
\hline Income & 0.133 & 0.178 & 0.5517 & 0.467761 \\
\hline M Status & 0.677 & 0.201 & 11.4007 & 0.003586 \\
\hline Duration & -0.119 & 0.178 & 0.4502 & 0.511258 \\
\hline MADRS & 0.719 & 0.193 & 13.9038 & 0.001670 \\
\hline Constant & 0.835 & 0.893 & 0.8729 & 0.363233 \\
\hline \multicolumn{7}{|c}{ Table 5. Pain Interference Correlation } \\
\hline
\end{tabular}

Correlation Coefficient: $\mathrm{R} 2=0.77$

\begin{tabular}{|c|c|c|c|c|}
\hline Variable & Coefficient & Std. Error & F-Test & P-Value \\
\hline Age & -0.160 & 0.154 & 1.0748 & 0.313596 \\
\hline Sex & 0.188 & 0.185 & 1.0337 & 0.322754 \\
\hline Domicile & -0.635 & 0.360 & 3.1189 & 0.094344 \\
\hline Duration & -0.148 & 0.276 & 0.2872 & 0.598590 \\
\hline Education & -0.291 & 0.265 & 1.2068 & 0.286445 \\
\hline Employment & 0.180 & 0.360 & 0.2501 & 0.623054 \\
\hline Income & 0.326 & 0.317 & 1.0576 & 0.317395 \\
\hline M Status & 0.281 & 0.352 & 0.6361 & 0.435530 \\
\hline MADRS & -0.027 & 0.295 & 0.0086 & 0.927251 \\
\hline Constant & 0.812 & 1.591 & 0.2605 & 0.615987 \\
\hline Table 6.
\end{tabular}

Table 6. Correlation of Percentage of Pain Reduction

Correlation Coefficient: $\mathrm{R} 2=0.31$ 


\section{DISCUSSION}

In the present study, 100 patients with rheumatoid arthritis were assessed and grouped into 2 categories- 1 . Patient with depression and rheumatoid arthritis, 2. Patient with rheumatoid arthritis alone. The socio-demographic data and ratings of brief pain inventory were assessed across the group and the intensity of depression with the above variables were assessed within the group of depressive patients. $22 \%$ of the rheumatoid arthritis were depressed and this finding is similar to earlier studies, which reports depression as the common psychiatric disorder in rheumatoid arthritis (Murphy et al 1999,5 Creed F et al 19938). Contrary to this, there is one study which reports that depression is not more common in rheumatoid arthritis clinics than in other clinics (Hawley DJ, Wolffe et al). ${ }^{9}$ It differs from the study by Van Dyke MM et al,10 which the prevalence of depression was found much lower than reported by Chris Dickens et al $2003^{11}$ (39.5\%) and Frank RG et al (42\%). This was however found closer to another study, which reported $23 \%$ depression in patients with rheumatoid arthritis. In the present study, the mean duration of illness is 5.4 years. There was also no significant relation between duration of rheumatoid arthritis and the psychiatric morbidity or depression. Similar findings were also reported by Rasker JJ 2001. This is contrary to the view that patients with longer duration of the illness will have more disability and depression (Von Korff et al, 1992). In this study, there was no statistically significant relation between steroid use and psychiatric morbidity. This study was contradictory to the finding of an earlier study (Dinan et al, 1994).12 This may be due to the use of low dose of steroids. There was no significant relation with rheumatoid factor also; however, there were no previous studies to collaborate.

Among the 100 patients assessed, 90 of them reported pain. Comparison of character of pain, i.e. worst pain, least pain, present pain and average pain showed significant difference in patients with and without depression $(\mathrm{P}$ value= 0.008). Several early studies reported similar findings of increased pain level in rheumatoid arthritis patients with depression (Covic et al 20032, JC Packham et al 200213, Katz PP 199314).

Then the pain is moderate-to-severe and impairs function, patient reports more depressive symptoms and outcome of depression also worsens (Mathew J Bair et al, 2003). ${ }^{15}$ Similar to this in the present study, the pain intensity score and depression rating score are positively co-related. The view of considering the chronic pain as a mutant variety of depression and the use of antidepressant in the management of pain can be discussed on this background (McFarlane GJ et al). ${ }^{16}$ In the present study there is no positive relation between the age, education, employment, income and duration of rheumatoid arthritis with level of pain. Some earlier reports co-relate between the duration of illness, age and education status of the patient (Covic et al 2003). ${ }^{2}$

The score of degree of interference due to pain on different domains of life such as general activity, mood, enjoyment, interrelation etc. was significantly different in depressed group (P value $=0.004$ ) .

These results show the overlap between the depressive symptoms and the direct impact of pain. Responses of people with rheumatoid arthritis on widely used depression scales might be affected by somatic disease regardless of psychological status (Callahan LF et al, 1991). Pain interference score is positively correlated with level of depression. Depressed group also showed similar result, (P value $=0.004)$. This finding indicates the psychological dimension of pain perception. Depression in patients with pain is associated with more pain complaints (Mathew J Bair et al, 2003).

\section{Limitations}

1. This is not a prospective study. Hence, it is difficult to say the pain as a cause or as an effect of depression.

2. The study was conducted in a speciality clinic and the sample was not representative of rheumatoid arthritis patients in general population.

\section{CONCLUSION}

Depression is a common psychiatric morbidity among patients with rheumatoid arthritis. The intensity and percentage of pain reduction in rheumatoid arthritis patients with treatment are directly correlated with the intensity of depression.

\section{REFERENCES}

[1] Abdel-Nasser AM, Abd El-Azim S, Taal E, et al. Depression and depressive symptoms in rheumatoid arthritis patients: an analysis of their occurrence and determinants. Br J Rheumatol 1998;37(4):391-7.

[2] Blumer D, Heilbronn M. Chronic pain as a variant of depressive disease: the pain-prone disorder. J Nerv Ment Dis 1982;170(7):381-406.

[3] Dickens C, Jackson J, Tomenson B, et al. Association of depression and rheumatoid arthritis. Psychosomatics 2003;44(3):209-15.

[4] Dickens C, McGowan L, Clark-Carter D, et al. Depression in rheumatoid arthritis: a systematic review of the literature with meta-analysis. Psychosom Med 2002;64(1):52-60.

[5] Covic T, Adamson B, Spencer D, et al. A biopsychosocial model of pain and depression in rheumatoid arthritis: a 12-month longitudinal study. Rheumatology (Oxford) 2003;42(11):1287-94.

[6] Creed F. Psychological disorders in rheumatoid arthritis: a growing consensus? Ann Rheum Dis 1990;49(10):808-12.

[7] Harbuz MS, Korendowych E, Jessop DS, et al. Hypothalamo-pituitary-adrenal axis dysregulation in patients with rheumatoid arthritis after the dexamethasone/corticotrophin releasing factor test. J Endocrinol 2003;178(1):55-60.

[8] Hawley DJ, Wolfe F. Anxiety and depression in patients with rheumatoid arthritis: a prospective study of 400 patients. J Rheumatol 1988;15(6):932-41.

[9] Levenson JL. Psychological factors affecting medical condition. In: Tasman A, Kay J, Liberman JA. (eds). Psychiatry. Vol 2. Bangalore: John Wiley 2004:1648-9.

[10] Masi AT, Chrousos GP. Hypothalamic-pituitary-adrenal axis function in rheumatoid arthritis. J Rheumatol 1996;23:577-81.

[11] Bair MJ, Robinson RL, Katon W, et al. Depression and pain comorbidity: a literature review. Arch Intern Med 2003;163(20):2433-45. 


\section{Jemds.com}

[12] Murphy H, Dickens C, Creed F, et al. Depression, illness perception and coping in rheumatoid arthritis. J Psychosom Res 1999;46(2):155-64.

[13] Packham JC, Hall MA, Pimm TJ. Long-term follow-up of 246 adults with juvenile idiopathic arthritis: predictive factors for mood and pain. Rheumatology (Oxford) 2002;41(12):1444-9.

\section{Original Research Article}

[14] Rifkin A. Depression in physically ill patients. Don't dismiss it as 'understandable'. Postgrad Med 1992;92(3):147-54.

[15] Romano JM, Turner JA. Chronic pain and depression: does the evidence support a relationship? Psychol Bull 1985;97(1):18-34.

[16] Wolfe F. Psychological distress and rheumatic disease. Scand J Rheumatol 1999;28(3):131-6. 